\title{
RANCANG BANGUN SISTEM KONTROL BUCKET ELEVATOR BERBASIS MIKROKONTROLER
}

\author{
Oriza Candra*, Elfizon
}

\author{
Jurusan Teknik Elektro \\ Fakultas Teknik Universitas Negeri Padang \\ Padang
}

Email: *) orizacandraft@gmail.com

\begin{abstract}
Abstrak
Salah satu alat yang digunakan di PT. Semen Padang adalah bucket elevator. Bucket elevator tersebut bekerja menggunakan sistem kendali onf/off dengan memanfaatkan timer pada Programmable Logic Controller (PLC). Tujuan dari perancangan ini adalah membuat sistem kontrol bucket elevator sebagai alat transportasi material yang terintegrasi dalam suatu sistem kendali yang dapat bekerja secara otomatis (tidak bergantung seutuhnya pada manusia), sehingga proses pekerjaan dapat berlangsung terus menerus untuk mendapatkan kualitas produksi yang lebih baik.

Sistem kontrol bucket elevator yang dirancang memanfaatkan sistem kendali tertutup (close loop), dimana jumlah atau kapasitas material yang ada pada hopper akan menjadi umpan untuk mentransportasikan material. Pada saat material dalam keadaan kosong (dengan jarak deteksi antara sensor dengan permukaan material lebih dari $20 \mathrm{~cm}$ ), maka sistem secara otomatis akan mengaktifkan motor penggerak bucket elevator untuk mentransportasikan material kedalam hopper. Sebaliknya ketika material telah mencapai posisi penuh yang dideteksi oleh sensor dengan jarak $5 \mathrm{~cm}$, maka sistem akan menghentikan kinerja dari motor penggerak tersebut.

Berdasarkan hasil pengujian, maka dihasilkan kesimpulan bahwa bucket elevator dapat memindahkan material dengan persentase nilai error yang kecil yaitu sebesar 1,6\% dari sampel 2000 gram. Selain itu, dengan menggunakan sistem kendali tertutup, maka sistem kendali bucket elevator mampu bekerja lebih efektif dan efisien dalam mengkonsumsi energi serta tidak menyebabkan pengurangan masa pakai motor penggerak.
\end{abstract}

Keywords-bucket elevator; close loop

\section{Pendahuluan}

Perkembangan teknologi saat ini telah menuai prestasi untuk terus berkarya dan berinovasi dalam segala aspek pengetahuan. Pengetahuan tersebut meliputi ilmu teknik, ilmu kedokteran, ilmu komunikasi dan masih banyak lagi ilmu pengetahuan lain yang terus dikembangkan, dengan tujuan untuk mempermudah urusan dan pekerjaan manusia. Perkembangan teknologi tersebut telah diterapkan dalam dunia industri, baik itu industri skala menengah, maupun industri skala besar. Perkembangan teknologi dalam dunia industri, dapat diihat pada industri semen, salah satu contohnya adalah PT. Semen Padang yang telah menggunakan perangkat-perangkat pendukung yang dioperasikan secara otomatis tanpa adanya interfensi langsung dari manusia, sehingga industri tersebut tetap konsisten dalam berproduksi dan mampu meningkatkan hasil produksi kedepannya.

Tahapan produksi pada PT. Semen Padang diantaranya adalah tahap penambangan dan penyimpanan material atau bahan baku, tahap penggilingan awal atau pencampuran, tahap pembakaran, tahap penggilingan akhir, dan tahap pengantongan. Material yang telah diambil dari area penambangan akan disalurkan ke tempat penyimpanan material (stockpile atau storage) sebelum masing-masing material ini dicampur dan digiling menjadi satu dalam mesin raw mill, sehingga menjadi butiran yang halus dan siap untuk dibakar dalam rotary kiln.

Material yang ada pada stockpile dibawa ke raw mill menggunakan belt conveyor. Setelah material sampai di raw mill, material tersebut diangkat atau dibawa ke bak penampungan (hopper) yang berada di puncak raw mill menggunakan bucket elevator atau disebut juga bucket conveyor. Menurut Zainuri (2009: 108), “Bucket elevator adalah suatu alat atau mesin pengangkut material kering dan berbentuk serbuk (butiran-butiran kecil, maupun berbentuk bongkahan) secara vertikal, baik dari tempat yang rendah ke tempat yang relatif lebih tinggi atau sebaliknya, dengan sudut kemiringannya lebih besar dari $70^{\circ}$ dari bidang datar". Prinsip kerja dari bucket elevator tersebut adalah menyalurkan dan mengangkat material dari tempat penyimpanan menuju bak penampungan dalam rentang waktu tertentu. Durasi atau waktu yang digunakan untuk mengoperasikan bucket elevator 
tergantung pada ukuran atau volume bak penampungan dari setiap material. Perbandingan tersebut mengandung arti, bahwa jumlah material untuk setiap $1 \mathrm{~m}^{3}$ yang berada dalam bak penampungan adalah sebesar 1,3 ton. Sementara itu, rentang waktu yang dibutuhkan oleh bucket elevator untuk mengisi penuh bak penampungan dengan ukuran $450 \mathrm{~m}^{3}$ adalah sekitar 1,5 sampai 2 jam. Material yang telah terisi penuh tersebut ditargetkan akan habis dalam rentang waktu 2 sampai 3 jam, dan setelah itu bucket elevator akan dioperasikan kembali.

Bucket elevator yang terdapat di PT. Semen Padang dioperasikan menggunakan PLC (Programmable Logic Controller) dengan sistem kendali on/off. Sistem kendali ini akan mengoperasikan motor penggerak bucket elevator berdasarkan waktu tunda pada pemrograman PLC, biasanya waktu tunda tersebut berkisar antara 2 sampai 3 jam, tergantung kapasitas material yang bisa ditampung oleh bak penampungan. Kelemahan dari sistem ini adalah ketika dalam rentang waktu yang telah ditentukan diatas ( 2 sampai 3 jam), ternyata material yang berada dalam bak penampungan masih ada, namun sistem akan tetap mengoperasikan motor penggerak dari bucket elevator tersebut. Jika motor dioperasikan secara on/off dalam rentang waktu yang relatif singkat, maka dapat mengakibatkan pemborosan energi listrik, serta dapat mengurangi usia atau jangka pakai dari motor penggerak bucket elevator tersebut. .

Berkenaan dengan sistem kontrol bucket elevator, pabrik Indarung V PT. Semen Padang rata-rata mengalami kerusakan pada otak atau kontroler dari sistem kontrolnya". Kontroler yang digunakan berupa PLC buatan FLS, sementara itu suku cadang dari PLC tersebut jarang ada di pasaran dan harganya cukup mahal. Selain itu, penggunaan PLC pada industri umumnya digunakan sebagai pengontrolan proses produksi yang kompleks dan besar, namun penggunaan PLC sebagai sistem kontrol bucket elevator kurang tepat guna dalam segi biaya dan manfaat dari PLC itu sendiri. Harga PLC rata-rata diatas satu juta, namun sistem kontrol bucket elevator hanya memanfaatkan 2 sampai 4 output digital pada PLC, yaitu sebagai pengontrol motor penggerak dari bucket elevator. Menurut Junia Rangga Nurel (2010) sistem kontrol lift digunakan di gedung-gedung bertingkat umumnya menggunakan sistem kontrol PLC (Programmable Logic Controller). Dalam membuat prototipe ini memberikan alternatif untuk menggantikan peran PLC dalam mengendalikan proses Lift bekerja, yang menggunakan Atmel Mikrokontroler ATMega8535

Kelemahan dari sistem ini dapat diatasi dengan menginovasi sistem kontrol dan cara kerja dari bucket elevator tersebut. Sistem yang ditawarkan untuk mengatasi kekurangan sistem sebelumnya adalah cara kerja pengisian bak penampungan menggunakan sistem kendali close loop, dimana sistem ini akan bekerja secara otomatis sesuai dengan keadaan atau jumlah material yang ada didalam bak penampungan. Sistem ini menggunakan mikrokontroler sebagai pengontrol pengoperasian bucket elevator, serta dilengkapi dengan satu unit sensor jarak ultrasonik tipe PING dan satu unit sensor infrared. Sensor PING dipasang pada bagian atas bak penampungan yang berfungsi sebagai pendeteksi material yang ada didalam bak penampungan disaat material tersebut telah penuh.

Selain itu, sensor PING juga difungsikan sebagai pendeteksi kapasitas atau jumlah (volume) material yang ada didalam bak penampungan dengan cara mengurangi volume total bak penampungan dengan volume bak penampungan yang belum terisi (bagian kosong) berdasarkan perubahan jarak antara sensor PING dengan permukaan material tersebut. Sedangkan sensor infrared yang dipasang pada bagian bawah bak penampungan berfungsi sebagai pendeteksi material didalam bak penampungan apabila telah kosong. Hasil pembacaan dari masing-masing sensor tersebut akan dikirimkan ke mikrokontroler untuk diproses, dan kemudian mikrokontroler akan memberikan perintah kepada masing-masing driver motor untuk bekerja sesuai fungsinya, baik untuk mengoperasikan atau menghentikan putaran motor penggerak bucket elevator itu sendiri.

Sesuai dengan latar belakang yang telah diuraikan, maka yang merupakan pokok permasalahan dari penelitian ini adalah merancang dan membangun sistem kontrol bucket elevator menggunakan mikrokontroler.

\section{Tujuan}

Penelitian ini bertujuan Merancang bucket elevator menggunakan kendali close loop dengan memanfaatkan sensor ultrasonik PING dan infrared sebagai pendeteksi material didalam bak penampungan, serta mikrokontroler ATmega8535 sebagai sistem kontrolnya. Merancang dan membuat program sistem kontrol bucket elevator agar dapat bekerja secara otomatis dengan memanfaatkan sensor ultrasonik PING dan infrared. Meneliti, menguji dan menganalisa kinerja bucket elevator dalam Mentransportasikan material.

\section{Metode \\ A. Bucket Elevator}

1. Pengertian Bucket Elevator

Menurut Zainuri (2009: 108), "Bucket elevator (disebut juga bucket conveyor) adalah pesawat angkut untuk jenis muatan curah (bulk load) secara vertikal atau dengan kemiringan (incline) lebih dari $70^{\circ}$ dari bidang datar". Bucket elevator khusus untuk mengangkut berbagai macam material berbentuk serbuk, butiran-butiran kecil dan bongkahan, seperti semen, pasir, batu bara, tepung, gula dan sebagainya. Alat ini dapat digunakan untuk menaikkan atau menurunkan material dengan ketinggian sampai 50 meter, kapasitas muatannya bisa mencapai 50 $\mathrm{m}^{3} / \mathrm{jam}$ dan konstruksinya dapat mencapai posisi vertikal. 
Bentuk dan konstruksi bucket elevator ditunjukkan pada Gambar 1.

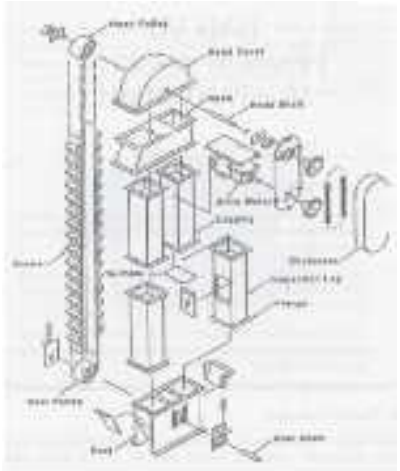

Gambar 1. Konstruksi Bucket Elevator (Zainuri, 2009: 164)

Jenis-jenis Bucket Elevator

Berdasarkan jenis material

Berdasarkan jenis material, bucket elevator yang biasa digunakan di industri terbagi menjadi tiga jenis, yaitunya:

1) Deep bucket

Deep bucket digunakan untuk bahan atau material yang sangat kering dan mudah mengalir. Pemasangan bagian penarik materialnya dipasang dengan sudut pemotongan sebesar $65^{\circ}$. Bentuknya dapat dilihat pada Gambar 2.

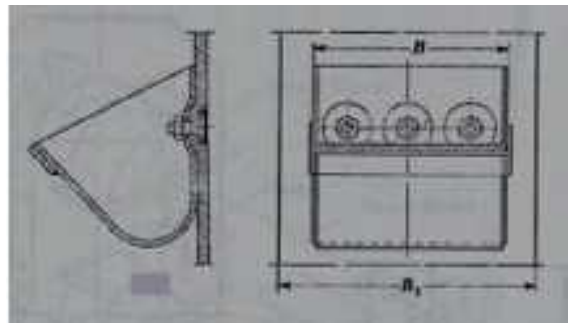

Gambar 2. Deep Bucket Conveyor

(Zainuri, 2009: 166)

\section{2) Shallow bucket}

Shallow bucket digunakan untuk bahan atau material yang mengandung uap air. Pemasangan bagian penarik materialnya dipasang dengan sudut pemotongan sebesar $45^{\circ}$. Shallow bucket dapat dilihat pada Gambar 3 .

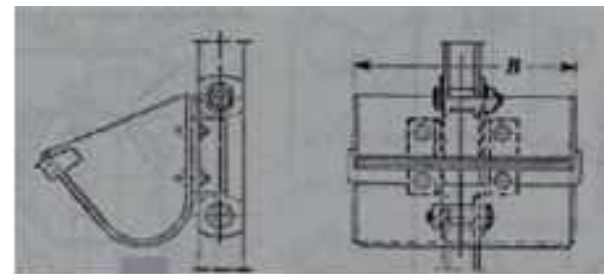

Gambar 3. Shallow Bucket Conveyor

(Zainuri, 2009: 166)

\section{3) V-bucket}

$V$-bucket digunakan untuk bahan atau material yang berat. Bentuk atau konstruksi dari $v$-bucket seperti yang terlihat pada Gambar 4.

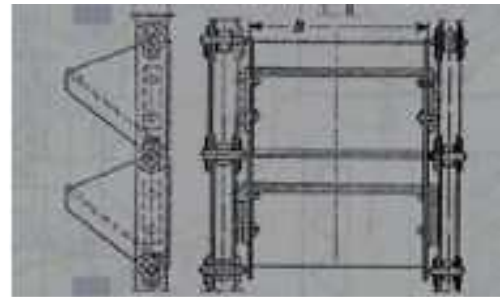

Gambar 4. V-bucket Conveyor (Zainuri, 2009: 166)

Berdasarkan sistem transmisi

Berdasarkan sistem transmisi, bucket elevator dibedakan menjadi dua jenis, yaitunya menggunakan transmisi belt dan menggunakan transmisi rantai. Keduanya mempunyai kekurangan dan kelebihannya masingmasing. Pertimbangan utama untuk memilih salah satu dari kedua jenis tersebut adalah faktor temperatur material yang diangkut, transmisi yang dihantarkan, perawatan dan usia pakai.

Jenis bucket yang akan digunakan adalah deep bucket, karena khusus dirancang untuk material kering yang berbentuk butiran halus, butiran sedang, maupun bongkahan. Di industri semen, contoh material tersebut seperti pasir besi, batu bara, batu kapur, gipsum, sedangkan material yang digunakan untuk pengujian nanti adalah pasir, karena tekstur pasir sama seperti pasir besi yang terbentuk dari butiran-butiran kecil. Sementara itu, untuk sistem transmisi prototype bucket elevator itu sendiri menggunakan sistem transmisi rantai, karena sistem transmisi rantai mempunyai beberapa kelebihan dibandingkan dengan transmisi belt. Kelebihan menggunakan transmisi rantai adalah sebagai berikut:

1) Kemungkinan terjadinya muai panjang akibat suhu material yang tinggi relatif kecil.

2) Kemungkinan terjadinya slip pada sistem transmisi sangat kecil, karena roda penggerak menggunakan gear, sehingga daya motor penggerak akan diteruskan dengan baik.

3) Kebutuhan perawatan lebih sedikit, karena kemungkinan terjadi kerusakan pada rantai relatif kecil.

4) Usia pakai lebih lama.

Perhitungan Rancangan Mekanik Bucket Elevator Bucket elevator yang terdapat di PT. Semen Padang memiliki ukuran atau dimensi yang berbeda pada masingmasing pabriknya. Ukuran bucket elevator yang menjadi objek penelitian adalah bucket elevator yang terdapat di raw mill pabrik Indarung V. Bucket elevator tersebut memiliki ukuran alas (bagian bawah) dengan panjang 114 $\mathrm{cm}$, lebar $108 \mathrm{~cm}$ dan tinggi $840 \mathrm{~cm}$. Pada Penelitian ini, skala atau perbandingan antara bucket elevator yang akan dibuat dengan bucket elevator yang diteliti adalah 1 : 5 (cm). Skala tersebut mengandung arti bahwa, ukuran 1 $\mathrm{cm}$ pada rancangan sama dengan $5 \mathrm{~cm}$ pada bucket elevator yang diteliti. Berdasarkan hal tersebut, maka 
didapatkanlah perancangan mekanik, dengan ukuran panjang alas $19 \mathrm{~cm}$, lebar $18 \mathrm{~cm}$ dan tinggi $140 \mathrm{~cm}$.

a. Perhitungan dimensi bucket

$i_{0}=\frac{Q \cdot u}{3,6 \cdot v \cdot \mu \cdot \varphi}$

Keterangan:

$\mathrm{i}_{0}=$ volume atau kapasitas isi bucket (liter)

$\mathrm{Q}=$ kapasitas pemindahan yang diinginkan

$$
\begin{aligned}
& \alpha=\text { jarak antar bucket } \\
& v=\text { kecepatan belt/rantai }(\mathrm{m} / \mathrm{s}) \\
& \rho=\text { masa jenis material curah }\left(\mathrm{kg} / \mathrm{cm}^{3}\right) \\
& \varphi=\text { effisiensi pembebanan } \text { bucket }=0,9
\end{aligned}
$$

Berdasarkan persamaan 1, maka berat total material yang dapat dibawa oleh 1 bucket dapat dihitung dengan persamaan persamaan berikut:

$P_{\mathrm{L}}=i_{0} \cdot p \cdot \varphi$

Keterangan:

$\mathrm{P}_{\mathrm{c}}=$ berat material

$$
\begin{aligned}
& \mathrm{i}_{0}=\text { volume atau kapasitas isi bucket (liter) } \\
& \rho=\text { masa jenis material curah }\left(\mathrm{kg} / \mathrm{cm}^{3}\right) \\
& \varphi=\text { effisiensi pembebanan } \text { bucket }=0,9
\end{aligned}
$$

Perancangan suatu alat terlebih dahulu dibuat suatu konsep agar tergambar secara jelas mengenai ruang lingkup pembahasan tersebut, dimana sebagai medianya adalah berupa blok diagram keseluruhan. Secara garis besar, blok diagram dari rangkaian bucket elevator ditunjukkan pada Gambar 5

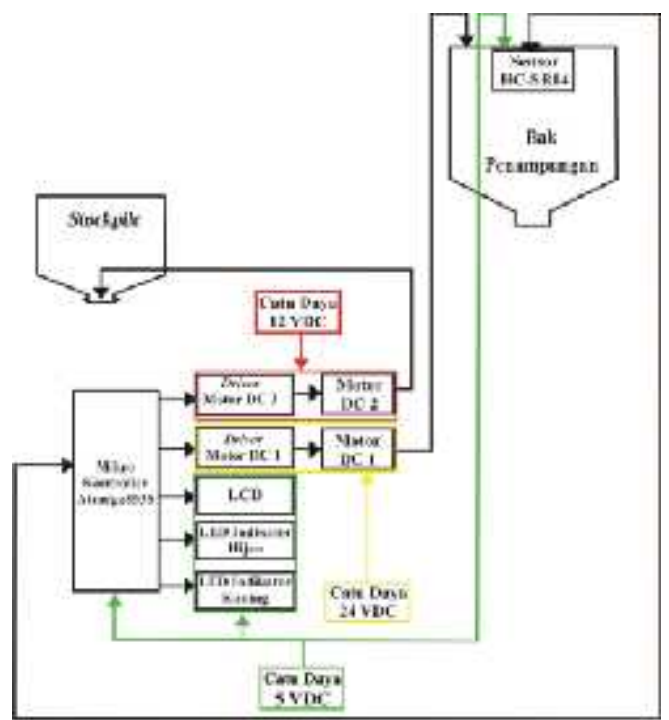

Gambar 5. Blok Diagram Sistem Kerja Bucket Elevator

b. Perhitungan spesifikasi motor penggerak bucket elevator

Perhitungan spesifikasi motor yang digunakan untuk menggerakkan bucket elevator dapat dijelaskan sebagai berikut:

Kapasitas material pasir (sampel) berdasarkan ukuran

$$
\begin{aligned}
& \text { bak penampungan } \\
& =2800 \mathrm{~g}+1800 \mathrm{~g}=4600 \mathrm{~g} \\
& \text { - Berat bucket }\left(\mathrm{P}_{\mathrm{c}}\right)=150 \mathrm{~g} \mathrm{x} \\
& 20=3000 \mathrm{~g} \\
& \text { - } \quad \text { Berat rantai (sistem transmisi) = } \\
& 280 \mathrm{~g} \text { x } 2=560 \mathrm{~g} \\
& =8160 \mathrm{~g}=8,16 \mathrm{Kg} \\
& \text { Berat total pembebanan }=4600 \\
& \mathrm{~g}+3000 \mathrm{~g}+560 \mathrm{~g}
\end{aligned}
$$

Analisa spesifikasi motor penggerak bucket elevator dapat dihitung menggunakan persamaan berikut ini:

$$
\text { - } \text { Torsi motor }(\tau) \quad=\mathrm{F}
$$$$
1
$$

$$
\begin{aligned}
& =(\mathrm{m} \cdot \mathrm{g}) \cdot 1 \\
& =\left(8,16 \mathrm{Kg} \cdot 9,81 \mathrm{~m} / \mathrm{s}^{2}\right) \cdot 0,91 \mathrm{~m} \\
& =72,8 \mathrm{Nm}
\end{aligned}
$$

$$
\begin{aligned}
& \text { Jumlah putaran }=\theta \cdot\left(\frac{1 p}{2 \pi r}\right) \\
& =\theta_{0} \tau+\frac{1}{2} u \cdot r^{2} \cdot\left(\frac{1 p}{2 \pi r}\right) \\
& =100 r \cdot\left(\frac{1 p}{2 \pi r}\right) \\
& =15,9 \text { putaran }
\end{aligned}
$$

\section{c. Diagram alir (Flowchart)}

Flowchart merupakan tahapan awal sebelum melakukan pembuatan program secara keseluruhan. Flowchart berisikan setiap langkah dan kemungkinan-kemungkinan yang terjadi, yang intinya adalah menjelaskan urutanurutan proses kerja dari alat yang akan dibuat. Selain itu, flowchart juga berfungsi sebagai acuan dalam membuat listing program dan instruksi-instruksi dari program yang akan dibuat. Bentuk flowchart sistem kerja dan flowchart pemrograman dari tugas akhir ini dapat dilihat pada Gambar 6. 


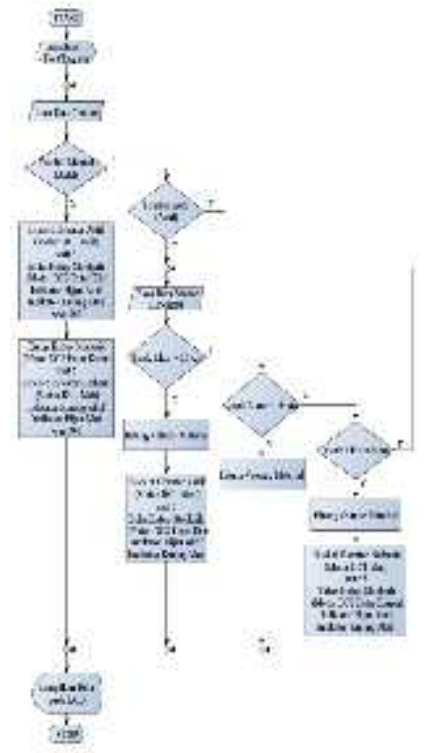

Gambar 6. Flowchart Sistem Kontrol Bucket Elevator

Secara keseluruhan, flowchart pada Gambar 6 diatas dapat dijelaskan sebagai berikut:

\section{a) START}

Program diawali dengan START yang berarti rangkaian kontrol diaktifkan.

b) Inisialisasi port/register (deklarasi variabel) Variabel adalah suatu simbol dalam program yang berfungsi untuk mewakili suatu nilai/menyimpan nilai tertentu yang sifatnya dinamis, dapat berubah-ubah selama program dijalankan. Deklarasi variabel bertujuan agar compiler mengenalinya, sedangkan inisialisasi variabel bertujuan untuk memberikan nilai pada variabel. Gambar 7 merupakan pendeklarasian dan inisialisasi variabel pada flowchart sistem kontrol bucket elevator

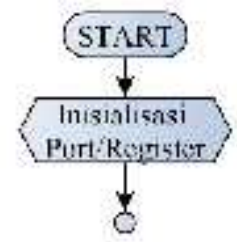

Gambar 7. Flowchart Deklarasi dan Inisialisasi Program

c) Baca data tombol

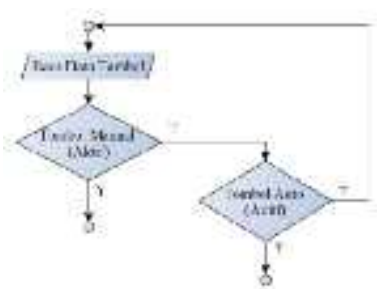

Gambar 8. Flowchart Baca Data Tombol

Tahap ini sistem kontrol akan diaktifkan berdasarkan penekanan tombol pada panel kontrol. Pada saat pengguna melakukan input yaitu dengan cara menekan tombol pada panel, maka mikrokontroler akan membaca data input kemudian akan mengaktifkan sistem kerja sesuai dengan input (masukan). Pada sistem ini terdapat beberapa kemungkinan yang akan terjadi ketika pemasukan input tombol, diantaranya:

(1) Tombol manual

Ketika tombol manual ditekan, maka sistem bekerja berdasarkan waktu tunda. Motor DC1 aktif untuk menggerakakkan bucket elevator, kemudian motor DC2 aktif untuk membuka katup pada stockpile. Setelah beroperasi selama waktu yang telah ditentukan (5 menit), maka motor DC2 menutup katup pada stockpile serta motor DC1 akan berhenti beroperasi. Hal ini ditunjukkan pada Gambar 49 dibawah ini:

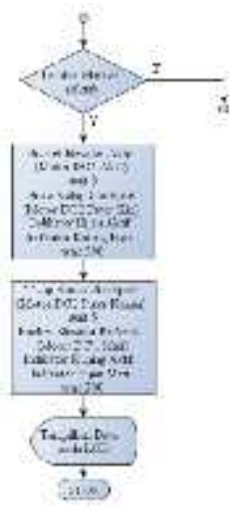

Gambar 9. Flowchart Tombol Manual

(2) Tombol auto

Ketika tombol auto ditekan, maka sistem akan bekerja otomatis berdasarkan pembacaan sensor HC-SR04. Gambar 10 di bawah ini menunjukkan flowchart sistem kera berdasarkan tombol auto.

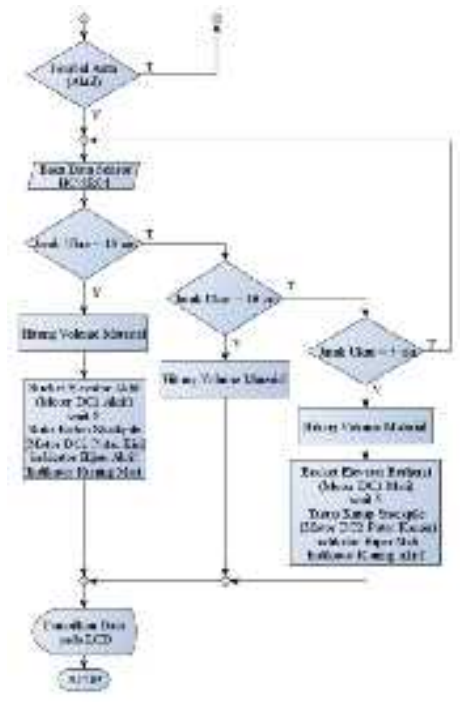

Gambar 10. Flowchart Tombol Auto

Hasil pembacaan sensor HC-SR04 berupa sinyal analog yang akan dikirim menuju PIN ADC mikrokontroler. Untuk mengolah sinyal tersebut sesuai pemrograman, maka mikrokontroler harus mengkonversi tegangan analog dari sensor menjadi sinyal digital. Setelah 
dikonversi, barulah sinyal dari sensor dapat dibaca oleh mikrokontroler, sehingga dapat diketahui apakah jarak ukur sensor terhadap material pada bak penampungan (hopper) telah sesuai dengan setpoint yang telah ditetapkan atau belum.

Sensor HC-SR04 akan aktif secara terus-menerus mendeteksi kapasitas didalam bak penampungan. Kapasitas material dihitung dengan cara mengurangi volume total bak penampungan dengan volume bak penampungan yang masih kosong berdasarkan perubahan jarak antara sensor HC-SR04 dengan permukaan material. Perubahan jarak tersebut diasumsikan menjadi nilai tinggi (t) untuk mencari volume bak penampungan dalam keadaan kosong. Formulasi untuk menghitung volume tersebut berdasarkan persamaan 10 dan 11 pada bab II (landasan teori), sehingga perhitungannya dapat dijelaskan sebagai berikut:

$$
\begin{aligned}
& \text { - Volume balok } \\
& =600 \mathrm{~cm}^{3} \\
& V=p \cdot l \text {. I } \\
& \text { - Volume limas terpancung } \\
& V=\frac{1}{3} \cdot[(L+A+\sqrt{D}) \\
& V=\frac{1}{3} \cdot 8(400+25+\sqrt{100}) \\
& =1.160 \mathrm{~cm}^{3} \\
& \text { - Volume total bak } \\
& \mathrm{V}_{\mathrm{I}}=\mathrm{V} \text {. Balok }+ \text { V. Limas Terpancung } \\
& =600 \mathrm{~cm}^{3}+1.160 \mathrm{~cm}^{3} \\
& =1.760 \mathrm{~cm}^{3}
\end{aligned}
$$

(a) Proses ketika jarak ukur sensor HC-SR04 dengan permukaan material sebesar $15 \mathrm{~cm}$

Sensor HC-SR04 mulai menghitung volume material ketika bagian bawah bak penampungan yang berbentuk limas terpancung telah terisi. Jarak ukur permukaan material dengan sensor diasumsikan sebagai nilai tinggi (t) untuk menghitung volume bak penampungan yang berbentuk balok. Gambar 49 dibawah ini merupakan flowchart perhitungan volume bak penampungan ketika jarak ukur sensor terhadap permukaan material sebesar 15 $\mathrm{cm}$.

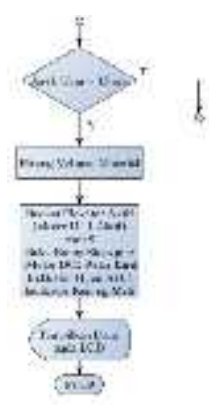

Gambar 11. Flowchart Jarak Pengukuran Sebesar $15 \mathrm{~cm}$ (b) Proses ketika jarak ukur sensor HC-SR04 dengan permukaan material sebesar $10 \mathrm{~cm}$

Sama halnya dengan menghitung volume dengan jarak 15 $\mathrm{cm}$ diatas, maka jarak ukur permukaan material dengan sensor sebesar $10 \mathrm{~cm}$ juga diasumsikan sebagai nilai tinggi (t) untuk menghitung volume bak penampungan. Hal ini dapat dilihat pada Gambar 12 dibawah ini:

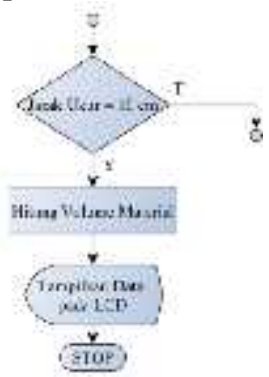

Gambar 12. Flowchart Jarak Pengukuran Sebesar $10 \mathrm{~cm}$
(c) Menghitung volume ketika jarak ukur $5 \mathrm{~cm}$ (material penuh)

Perhitungan volume dengan jarak $5 \mathrm{~cm}$ ini merupakan perhitungan volume material didalam bak penampungan dalam kondisi penuh. Ketika material telah penuh, maka mikrokontroler akan memberi perintah kepada driver motor DC2 untuk menutup katup pada stockpile, serta memberikan perintah kepada driver motor DC2 untuk menghentikan putaran motor DC2 (motor penggerak bucket elevator). Kondisi ini akan ditandai dengan hidunya LED indikator kuning, serta ditampilkan tulisan "material penuh, bucket elevator off, mode operasi standbay". Hal ini menyatakan bahwa material telah terisi penuh, sistem akan standby dan akan beroperasi kembali ketika jarak ukur sensor sebesar $15 \mathrm{~cm}$. Gambar $13 \mathrm{di}$ bawah ini merupakan flowchart material didalam bak penampungan telah penuh.

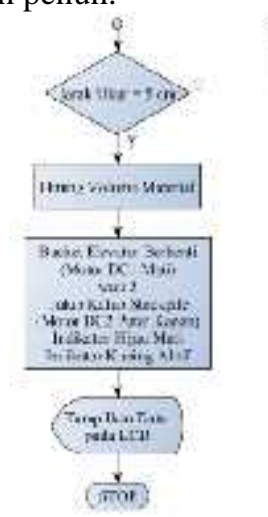

Gambar 13. Flowchart Material Telah Terisi Penuh

\section{Pembahasan}

Pengujian sistem secara keseluruhan bertujuan untuk mengetahui apakah perangkat keras dan program berjalan dengan baik. Hal ini dimaksudkan untuk melihat apakah sistem pengendalian berjalan sesuai dengan perencanaan 
dan sebagai indikasi penelitian ini berhasil. Pengujian ini dilakukan dengan melakukan pengujian daya tampung dan jumlah material bak penampung berdasarkan hasil pengukuran sensor HC-SR04. Berikut hasil pengujian sistem keseluruhan:

\section{Pengujian Transportasi Material}

Hasil pengujian pemindahan material oleh prototype bucket elevator terlihat pada Tabel 1 berikut ini:

Tabel 1. Pengujian Pemindahan Material

\begin{tabular}{llll}
\hline \multirow{2}{*}{ No } & $\begin{array}{l}\text { Material } \\
\text { (Gram) }\end{array}$ & $\begin{array}{l}\text { Lama Proses } \\
\text { (Menit) }\end{array}$ \\
\cline { 2 - 3 } & Input & Output & \\
\hline 1 & 2000 & 1925 & 1 \\
\hline 2 & 2000 & 1975 & 1 \\
\hline 3 & 2000 & 1975 & 1 \\
\hline 4 & 2000 & 1980 & 1 \\
\hline 5 & 2000 & 1980 & 1 \\
\hline 6 & 2000 & 1980 & 1 \\
\hline 7 & 2000 & 1985 & 1 \\
\hline 8 & 2000 & 1980 & 1 \\
\hline 10 & 2000 & 1990 & 1 \\
\hline
\end{tabular}

Pengujian pemindahan material dilakukan dengan cara menimbang sampel berupa material pasir sebanyak 2000 gram. Pasir tersebut dimasukkan ke stockpile. Proses pemindahan pasir dari stockpile ke bak penampungan dengan tinggi $100 \mathrm{~cm}$ rata-rata membutuhkan waktu selama 1 menit.

$$
\begin{aligned}
& =\frac{1}{2} \times 100 \% \\
& =1,6 \%
\end{aligned}
$$

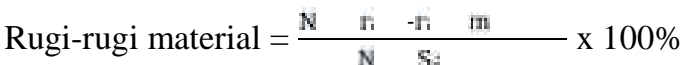

Berdasarkan dari pengujian dan analisa data diatas, dapat disimpulkan bahwa bucket elevator dapat memindahkan material dalam jumlah banyak dan memiliki sedikit rugirugi material yang dipindahkan sebesar $1,6 \%$. Kerugian ini bisa disebabkan oleh adanya material jatuh dalam proses pengangkatan material menuju bak penampungan.

\section{Penutup}

\section{Kesimpulan}

Berdasarkan hasil pengujian dan analisa terhadap sistem kontrol bucket elevator, maka dapat disimpulkan beberapa hal sebagai berikut:

1. Sistem kontrol bucket elevator telah dapat bekerja dengan baik dalam mentransformasikan material dari stockpile menuju bak penampungan (hopper).

2. Sistem kontrol bucket elevator telah dapat bekerja mengggunakan kendali close loop, dimana sensor HCSR04 dan infrared mendeteksi keadaan atau kapasitas material didalam bak penampungan, kemudian mikrokontroler mengontrol motor servo agar dapat membuka dan menutup udara dari kompresor, serta mengontrol motor DC1 untuk menggerakkan bucket elevator.

3. Pengujian dan analisa telah dilakukan, baik pengujian setiap blok maupun keseluruhan, dimana menghasilkan:

a. Sensor HC-SR04 telah bekerja dengan baik dalam mendeteksi material padat salah satunya semen.

b. Mikrokontroler ATmega8535 dan driver juga telah bekerja dengan baik

c. Program yang telah dibuat dapat bekerja sesuai dengan instruksi

d. Pengujian secara keseluruhan menghasilkan persentase rugi-rugi pemindahan yang kecil yaitu sebesar 1,6\% dari sampel 2000 gram.

\section{B. Saran}

Penulis menyadari banyaknya kekurangan yang ditemukan dalam pembuatan tugas akhir ini. Berikut akan dipaparkan beberapa saran-saran yang diharapkan dapat bermanfaat untuk mengembangkan aplikasi ini diantaranya adalah:

1. Sebaiknya ditambahkan sensor berat (loadcell) agar hasil pengukuran volume lebih akurat.

2. Catu daya yang digunakan hendaknya dipisahkan antara catu daya kontrol dan catu daya beban, karena arus yang digunakan untuk mengaktifkan motor adalah sebesar 3A dan ketika motor penggerak aktif dapat mempengaruhi sistem kontrol.

3. Untuk pengembangan selanjutnya, sebaiknya sistem ini dirancang menggunakan PC, sehingga besar nilai atau kapasitas material didalam bak penampungan ditampilkan dan disimpan di PC.

\section{Referensi}

[1] Bishop, Owen. 2004. Dasar-dasar Elektronika. Edisi Bahasa Indonesia. Jakarta: Erlangga.

[2] Chapman, Stephen J. 2002. Electric Machinery and Power System Fundamentals. New York: McGraw-Hill.

[3] Fitzgerald, dkk. 1992. Mesin-mesin Listrik. Jakarta : Erlangga.

[4] Hanif, Asral. 2013. Studi Kasus Alarm Gas Analyzer 5WIB850A1 pada Kiln Indarung. Laporan penelitian tidak diterbitkan. Padang: Politeknik Negeri Padang.

[5] Junia Rangga Nurel, 2010. Build a ptoyotype elevator control system based microcontroller ATMEGA8535 using C language, Naskah Publikasi. Yogyakarta. Sekolah Tinggi Manajemen Informatika

[6] Setiawan, Afrie. 2010. 20 Aplikasi Mikrokontroler ATmega8538 dan ATmegal6. Yogyakarta: Andi.

[7] Widiyanto, Danang. 2006. "Pengendalian Proses Pengisian Air Minum Kemasan Berbasis Programanle Logic Control". Jurnal Penelitian Nomor 10, (Online), (http://lib.ui.ac.id/file?file=digital/20177038-S28854Danang\%20 Widiyanto.pdf, diakses 10 Desember 2014).

[8] Zainuri, Muhib. 2009. Mesin Pemindah Bahan. Yogyakarta: Andi.

[9] Zuhal. 1988. Dasar Teknik Tenaga Listrik dan Elektronika Daya. Jakarta: Gramedia Pustaka Utama. 